\title{
Psychosocial areas of worklife and chronic low back pain: a systematic review and meta-analysis
}

\author{
Gabriele Buruck ${ }^{1 * \dagger} \mathbb{D}$, Anne Tomaschek ${ }^{2 \dagger}$, Johannes Wendsche ${ }^{3}$, Elke Ochsmann ${ }^{4}$ and Denise Dörfel ${ }^{2}$
}

\begin{abstract}
Background: The aim of this review was to synthesize the evidence on the potential relationship between psychosocial work factors from the Areas of Worklife (AW) model (workload, job control, social support, reward, fairness, and values) and chronic low back pain (CLBP; unspecific pain in the lumbar region lasting 3 months or longer).

Methods: We conducted a systematic literature search of studies in Medline, PsyclNFO, Web of Science, and CINAHL (1987 to 2018). Three authors independently assessed eligibility and quality of studies. In this metaanalysis, we pooled studies' effect sizes using a random-effects model approach and report sample size weighted mean Odds Ratios (ORs).

Results: Data from 18 studies $(N=19,572)$ was included in the analyses. We found no studies investigating associations between fairness or values and CLBP. CLBP was significantly positively related to workload $(\mathrm{OR}=1.32)$ and significantly negatively related to overall job control $(O R=0.81)$, decision authority $(O R=0.72)$, and two measures of social support (ORs $=0.75$ to 0.78 ), even in prospective studies. Skill discretion and reward did not significantly relate to CLBP. Moderation analyses revealed several variables (e.g., exposure time, mean age and sex) affecting these relationships.

Conclusions: Our results support employees' workload, job control, and social support as predictors of CLBP. In this line, these work factors should be considered when developing programs to prevent chronic low back pain. Future studies should apply measures of CLBP that are more precise, and investigate the full areas of work life (AW) factors in combination.
\end{abstract}

Keywords: Areas of work life, Chronic low back pain, Workload, Job control, Social support

\section{Background}

An important debate is still ongoing on the relationships between workplace factors and chronic low back pain (CLBP). According to Waddells' biopsychosocial model of pain [1] chronic pain represents a clinical syndrome that fundamentally differs from acute pain. This distinction applies not only to the duration of the symptoms but also to the presumed causing and maintaining factors of chronic pain, which are supposed to be diverse and include physical, psychological, and social variables.

\footnotetext{
* Correspondence: Gabriele.Buruck@fh-zwickau.de

${ }^{\dagger}$ Gabriele Buruck and Anne Tomaschek shared first authorship.

${ }^{1}$ Faculty of Health and Healthcare Sciences, Westsächsische Hochschule

Zwickau, University of Applied Sciences, 08012 Zwickau, Germany

Full list of author information is available at the end of the article
}

According to this, the model postulates that sensory inputs, cognitive factors, and emotional mechanisms modulate and drive pain development. Empirical findings support the biopsychosocial model: Different social and psychological factors seem to exert considerable influence on the development of chronic back pain $[2,3]$. For instance, occupational factors such as employment status, job dissatisfaction, work attitudes, and social support at the workplace have been found to be associated with CLBP [4*, 5-7]. However, information on the consistency of findings and the size of effects is still missing. Data synthesis with systematic reviews or meta-analyses provides the means to shed light on evidence about the antecedents of CLBP.

(c) The Author(s). 2019 Open Access This article is distributed under the terms of the Creative Commons Attribution 4.0 International License (http://creativecommons.org/licenses/by/4.0/), which permits unrestricted use, distribution, and reproduction in any medium, provided you give appropriate credit to the original author(s) and the source, provide a link to the Creative Commons license, and indicate if changes were made. The Creative Commons Public Domain Dedication waiver (http://creativecommons.org/publicdomain/zero/1.0/) applies to the data made available in this article, unless otherwise stated. 
With a world-wide prevalence of about 23\% [8, 9], CLBP is the most prevalent chronic pain condition and severe musculoskeletal disorder. It is associated with high social and economic costs, especially in highincome countries [10]. For instance, CLBP is the leading cause for a premature retirement of employees $[11,12]$. Furthermore, CLBP adversely affects the everyday life activities of individuals, their self-perception, and their contact to others [13]. In addition, CLBP is associated with increasing emotional distress and adoption of the sick role $[14,15]$. Although there is a great number of studies on the factors driving chronic back pain, a final summary and conclusion of results is difficult as chronic manifestation of pain was not defined consistently throughout these studies [16-18]. Therefore, this work aims to define the outcome more carefully (chronic low back pain) in order to increase comparability between the study results and their validity. We use a specific definition for CLBP that is pain in the lumbar region lasting 3 months or longer. This definition seems to be the most common approach and was used in several studies [19].

In addition to define CLBP precisely, investigating linkages between psychosocial workplace factors and CLBP needs a stronger conceptual and theoretical underpinning in order to increase validity of results. Psychosocial workplace stressors are consistently associated with signs and symptoms of musculoskeletal problems in central body regions and the back [20]. So far, most research on workrelated psychosocial risk factors was conducted within the Job-Demands-Control (JDC) framework [21, 22] assuming that high job strain (i.e., jobs characterized by a combination of high job demands and low job control) increases risks for developing low back pain (LBP; e.g. [23, 24]). The review and meta-analysis of Lang, Ochsmann [25] supported this by showing that high job demands $(\mathrm{OR}=1.32)$, low job control $(\mathrm{OR}=1.30)$, high job strain $(\mathrm{OR}=1.38)$, and, in addition, low social support (ORs $=1.19$ to 1.42$)$ are associated with increased risks for lower back symptoms. Similarly, Elfering and colleagues [26] found in a longitudinal study that low support from the supervisor increases the risk for LBP. In addition, in the study of Bernal and colleagues [27] effortreward imbalance was associated with more prevalent musculoskeletal disorders $(\mathrm{OR}=6.13)$ and low social support was related to incidents of back pain $(\mathrm{OR}=1.83)$. In sum, these findings support that LBP in general is related to psychosocial work factors such as high work demands, low job control, low levels of social support and, in addition, low reward. However, whether psychosocial work factors also promote the development of chronic pain is still debated [28]. Following this, there is an urgent need to review the literature on CLBP in more detail. Additionally, we consider it necessary to shed light on how the heterogeneous approaches of these studies might impact the findings.
Such a review is also necessary as the working world in western industrialized countries is currently undergoing many changes shaping the workplaces of employees. For instance, digitalization processes might lead to new work tasks and different kinds of work organization [29]. This leads to other work factors related to the health of employees becoming more and more important, for instance, procedural justice and work values [30]. It is therefore the aim of this review to synthesize findings on the associations between these 'new' work factors and CLBP, in addition to the "traditional" psychosocial risk factors in occupational health research (demand, control and social support; see [31]). A theoretical approach that integrates such new as well as established psychosocial work factors into a core framework is the Areas of Worklife (AW) model [32]. Based upon an extensive theory and study review, Leiter and Maslach [33] propose that fairness and work values have to be added to workload, job control, social support, and reward [21, $22,34]$ when explaining antecedents of job stress, burnout, and work-related strain symptoms more comprehensively [32]. More specifically, fairness refers to how fair and equitable decisions are made within the organization and values concern the fit or conflict between individual and organizational values.

Although the importance of the AW model as six organizational factors was mainly investigated for the development of burnout symptoms [35] there is some initial support for their association with (chronic) low back pain. First, Pohling, Buruck, Jungbauer, and Leiter [36] found that the factors workload, control, reward, and values are related to musculoskeletal complaints. Second, burnout as a unique affective response to chronic exposures of work stress [37] predicts the subsequent development of LBP [38] as well as musculoskeletal pain in several occupational groups [39]. In a large Finnish study [40] burnout was also an important correlate of musculoskeletal disorders among women even after adjusting for other contributing factors.

Therefore, the purpose of our study is to review and quantify the associations between employees' exposure to the six psychosocial work-related AW factors [32] and CLBP. Our review and meta-analysis adds the following contributions to the literature. In contrast to other reviews $[25,27,41]$, we consider the long-lasting and chronic states of lower back pain as outcome and define CLBP as pain in the lumbar region lasting for 3 months or longer [19]. While the previous reviews investigated associations between LBP and task-related as well as interpersonal work stressors, for instance, job demands, job control, job strain, social support, job security, and monotonous work, we extend this view and add fairness and values as predicting organizational variables. 


\section{Methods}

\section{Criteria for considering studies for the current review Search strategy}

The systematic literature search included the following databases: Medline (Pubmed), PsycINFO, Web of Science, and CINAHL. The search strategy was applied to all databases and combined three blocks of keywords: (1) the study population (occupational samples), (2) the outcome (general terms, e.g. musculoskeletal disorders and more sensitive terms, e.g. CLBP), (3) exposure (psychosocial work factors relying on the AW model [32];). Appendix 1 provides the search string. Since the formulation of the new biopsychosocial model of LBP by Waddel [1] launched a new area of publications, the search period started in 1987 and ended in January 2018, Week 3. In addition to the electronic search, reference lists of key review articles were inspected manually.

\section{Study selection}

Studies were included in the systematic review and the meta-analysis if they were (a) written in English or German and published in a peer-reviewed journal, (b) reported original data on associations between at least one of the psychosocial risk factors included in the AW model (workload, job control, social support, reward, values or fairness) and CLBP (pain in the lumbar region $\geq 3$ months; see [19]), and (c) used a sample of working adults (at least 18 years old). After the removal of duplicates, the literature search yielded a total of 13,232 records. All records were reviewed by title and by abstract. Subsequently, three of the authors (GB, DD, AT) conducted a full-text review of 673 records. Finally, 18 studies could be included in the review and meta-analysis. In contrast to the review of Lang et al. [25], which focused on prospective studies only, we also included cross-sectional studies to get further insights on the stability of effect sizes in a further moderator analysis. Figure 1 shows the flow chart of study selection.

\section{Quality assessment}

Three reviewers independently assessed the methodological quality of the 18 included studies (GB, DD, AT). We used an adapted version of the Scottish Intercollegiate Guidelines Network (SIGN) checklist. To adapt the SIGN checklist, we followed a previous review which analyzed occupational risk factors for musculoskeletal pain or complaints (see [27, 42-44]).

This scale included 8 items grouped into A. study objective/purpose, B. study design/population, C. exposure assessment, D. outcome assessment, and E. analysis and data presentation. See Table 7 in Appendix 2 for all items. Each item was rated as "positive" (when requirement was met), "negative" (when requirement was not met) or "unclear" (unsure if requirement was met). A score was obtained for each study by the sum of all positive responses (1 point each item). Studies were considered as high-quality $(++)$ with 8 positively evaluated items, medium-quality $(+)$ with 6 to 7 positively evaluated items, or low-quality (0) with less than 6 positively evaluated items (adapted from [27]).

\section{Data extraction}

For each study, we coded the reported effect size and its variance for relationships between psychosocial work factors and CLBP and, in addition, potential moderator variables.

Coding of effect sizes For cross-sectional studies, reported effect size estimates (e.g., correlation $r$, odds ratio $\mathrm{OR}$, risk ratio $\mathrm{RR}$, prevalence ratio $\mathrm{PR}$, or hazard ratio $\mathrm{HR}$ ) and their variances were extracted. We always used the estimates that were adjusted most comprehensively for confounders. The majority of studies $(k=14)$ reported effect sizes adjusted for age or sex, but only eight studies included both confounders (only age-adjusted: $k=5$; only sex-adjusted: $k=1$ ). For prospective studies, we coded lagged (prospective) effect sizes. If no effect size estimate was reported, we calculated it using other statistical information given in the studies with Comprehensive Meta-Analysis (CMA) software 2.2 (Biostat, Inc., Englewood, NJ). If a relationship was reported as insignificant, but not substantiated by statistical information, the effect size was coded as OR $=1$.

Coding of moderator variables The following variables were coded as moderators: year of publication, sample size $N$, occupation (blue, white, pink collar or mixed), country of origin/sampling, study design (cross-sectional or prospective), type of psychosocial work factor, duration of exposure (in months) for prospective studies, samples' mean age (in years) and sex distribution (percentage of females), and methodological quality of the study (see above).

\section{Statistical analyses}

We used $O R$ as effect size measure in this meta-analysis. If studies reported other types of effect size measures they were transformed into ORs with CMA software. Reported PRs, RRs, and HRs from prospective studies were considered as equivalent to ORs. We are aware that this procedure is warranted only if the incidence of an outcome is low [45]. However, incidences of CLBP in nonexposed groups, which are needed for transformation, were not reported in our sample of studies.

We calculated composite ORs whenever multiple associations between constructs of interest were reported. In these cases, we used the mean $O R$ and corrected its 


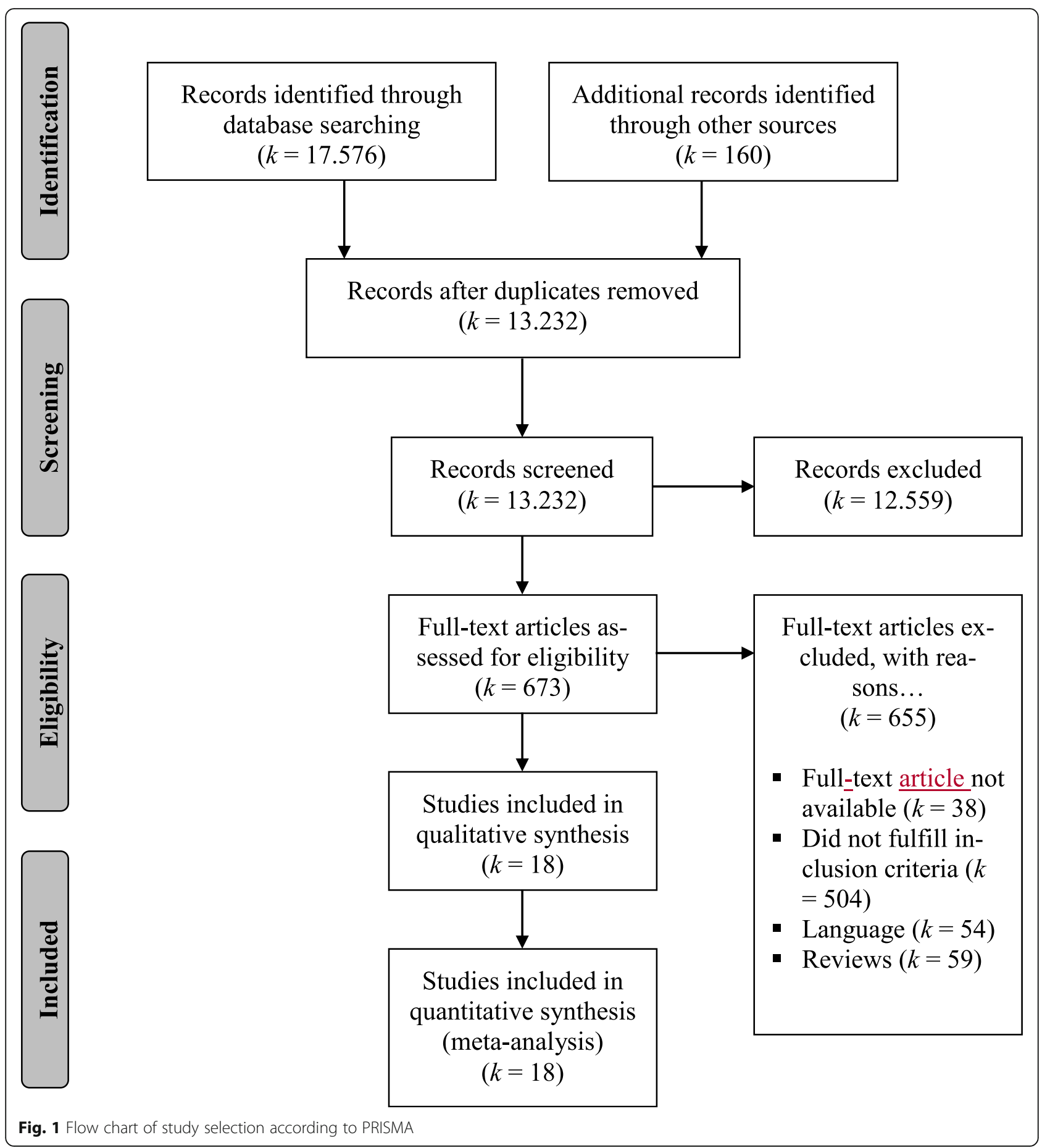

variance according to the formulas given by Borenstein et al. [46]. In our analyses this occurred for both dimensions of job control (i.e., decision authority and skill discretion) and social support (i.e., from colleagues and from the supervisor). This procedure is necessary because independency of effect sizes is required for pooling [46]. As correlations between dimensions of control and social support were only reported in the study of Eriksen et al. $\left(\left[47^{*}\right] ; \mathrm{rs}=.41\right)$ we used them as estimates for correction of variances.

We aggregated effect sizes according to the approach suggested by Hedges and Olkin [48] and calculated sample size weighted mean ORs with a random-effects model [46]. We report the number of studies $k$, the cumulative sample size $N$, the sample size weighted mean $O R$ and its $95 \%$ confidence interval $(C I)$. Moreover, we 
report 95\% prediction intervals (PI [46, 49];). In contrast to $95 \% \mathrm{CIs}$ as measure of precision, the $95 \%$ PI considers the range of effects that may be expected in future studies. Pooled ORs with 95\% CIs excluding zero are significant with $p<.05$.

To estimate heterogeneity in effect sizes, we calculated $Q$ - and $I^{2}$-statistics [46]. The $I^{2}$ indicates the proportion (percentage) of the observed variance in effects across the studies indicating consistency of findings [46]. Values of $I^{2} \geq 25 \%$ indicate some heterogeneity (25\%= low, $50 \%=$ moderate, $75 \%=$ high), pointing to potential moderator effects. We used subgroup analysis (Q-between-statistics) for categorical moderators and mixed effects meta-regression (unrestricted maximum likelihood method) for interval scaled moderators. In line with recommendations of Borenstein et al. [46], we further conducted sensitivity analyses and checked our data for potential publication bias (i.e., inspection of funnel plots, significance of Eggers regression intercept, trimand-fill-analysis). Moreover, we visualized the study results with forest plots. We conducted all analyses with CMA software 2.2 (Biostat, Inc., Englewood, NJ).

\section{Results}

\section{Study characteristics}

This systematic review aimed at a comprehensive investigation of the relationships between psychosocial work factors, by use of the AW model, and CLBP. However, we only found studies for the following job exposures: workload $(k=14)$, control $(k=13)$, social support $(k=$ $12)$, and only two studies for reward. Therefore, values or fairness as other psychosocial exposures of interest according to the AW model could not be examined. All studies used self-report measures of psychosocial job exposures. Table 1 summarizes the characteristics of the 18 independent studies ( $N=19,572$ employees). Most of them were published between 2000 and $2005(k=9$; 2005-2010: $k=6$, after 2010: $k=4$ ). The median samples size was 634 $(M=1087$, Range $=102$ to 7757$)$ with mainly mixed or pink-collar samples (each with $k=7$; blue collar with $k=4)$. Most studies were of European origin ( $k=11$; Asia: $k=4$; Australia/New Zealand: $k=1$; Northern America: $k=2$ ). The samples' mean age was 39 years (range: 32 to 52 ) with a mean proportion of $52 \%$ females. Altogether 10 studies used a prospective design (cross-sectional: $k=8$ ). Our quality assessment yielded that most studies had a medium $(k=12)$ or low $(k=5)$ study quality (high: $k=1$ ).

\section{Meta-analysis}

\section{AW factors and CLBP}

Table 2 shows the pooled ORs and heterogeneity statistics. We found that workload significantly and positively related to CLBP with low heterogeneity across the studies. The significant prediction intervals underline this high consistency of effects across studies. Job resources had a protective effect regarding CLBP $(O R s<1)$. However, the effects were only significant for the combined index of job control, for decision authority, and for all social support measures (combined, from colleagues, from supervisor) but not for skill discretion and for reward. Effect sizes for supervisor support showed low heterogeneity $\left(I^{2}<.01 \%\right)$, whereas effect sizes for the combined social support measures and for decision authority showed moderate heterogeneity $\left(I^{2} \mathrm{~s}: 65\right.$ to $\left.73 \%\right)$. Heterogeneity of effect sizes was high $\left(I^{2}=85 \%\right)$ for relationships between reward and CLBP which was also bolstered by insignificant prediction intervals.

\section{Moderator analyses}

We conducted a series of moderator analyses to investigate sources of heterogeneity and to check the stability of results further (Tables 3, 4, and 5). Because of low sample size $(k=2)$ moderator analyses for relationships between reward and CLBP were not warranted [46]. First, we found that pooled effect size estimates (ORs) were even significant in prospective studies (see Tables 3 and 4 and Fig. 2) with1.25 for workload, 0.77 for job control, 0.63 for decision authority, 0.78 for skill discretion, and 0.78 for social support. However, prospective relationships between colleague support and CLBP were not significant.

Occupation, study quality, and sample size were not detected as moderators affecting pooled effect size estimates. For some exposure-CLBP relationships, we found significant differences between countries. However, such effects might be spurious because of the low number of studies in the subcategories. Therefore, an interpretation of effects is not warranted [46].

Regarding the prospective studies, we found that duration of exposure (i.e., time between assessment of work-related factor and CLBP) affected the relationships between CLBP and between skill discretion as well as social support from colleagues (and the combined social support measure). However, the direction of effects was inconsistent. We do not interpret these results as these analyses were based on a low number of studies $(4 \leq k \leq$ 8 [46];). Year of publication was partially supported as moderator. That means that studies that were more novel reported stronger protective effects for relationships between CLBP and job control as well as colleague support. Moreover, the negative relationship between CLBP and job control was strengthened with an increasing mean age in the samples and the negative relationship between CLBP and skill discretion was strengthened with increasing number of males in the samples. 
Table 1 Study characteristics

\begin{tabular}{|c|c|c|c|c|c|c|c|c|c|}
\hline Reference & $N$ & Occupation & Country & $\begin{array}{l}\text { Mean age } \\
\text { (Years) }\end{array}$ & $\begin{array}{l}\text { Females } \\
(\%)\end{array}$ & Design & Response rate & Exposures & $\begin{array}{l}\text { Study } \\
\text { quality }\end{array}$ \\
\hline $\begin{array}{l}\text { Aghilinejad, } \\
2015\left[4^{*}\right]\end{array}$ & 185 & blue collar & Iran & 36 & 0 & $P$ & unknown & $W+C+S$ & + \\
\hline $\begin{array}{l}\text { Alexopoulos, } \\
2003\left[50^{*}\right]\end{array}$ & 351 & pink collar & Greece & 37 & 81 & CS & $90 \%$ & $\begin{array}{l}W+C(D A)+ \\
S(C, S S)\end{array}$ & + \\
\hline $\begin{array}{l}\text { Brage, } 2007 \\
{\left[51^{*}\right]}\end{array}$ & 1152 & $\begin{array}{l}\text { mixed } \\
\text { collar }\end{array}$ & Norway & 35 & 50 & $P$ & 98\% (permission of register follow-up) & C & + \\
\hline $\begin{array}{l}\text { Cameron, } 2008 \\
{\left[52^{*}\right]}\end{array}$ & 303 & pink collar & Canada & 52 & 96 & CS & $61 \%$ & $C(\mathrm{DA})$ & - \\
\hline $\begin{array}{l}\text { Elders, } 2001 \\
{\left[53^{*}\right]}\end{array}$ & 288 & blue collar & Netherlands & 36 & 0 & CS & 85\% (baseline) & $W+C$ & - \\
\hline $\begin{array}{l}\text { Eriksen, } 2004 \\
{\left[54^{*}\right]}\end{array}$ & 4266 & pink collar & Norway & 45 & 96 & $P$ & $\begin{array}{l}\text { 62.3\% (baseline) } 89.3 \text { (follow-up 1) } 85.6 \\
\text { (follow-up 2) }\end{array}$ & $S(S)$ & + \\
\hline $\begin{array}{l}\text { Eriksen, } 2006 \\
{\left[47^{*}\right]}\end{array}$ & 779 & pink collar & Netherlands & 40 & 84 & CS & $60 \%$ & $\begin{array}{l}W+C(D A \\
S D)+S(C, S S)\end{array}$ & + \\
\hline $\begin{array}{l}\text { Feng, } 2007 \\
{\left[55^{*}\right]}\end{array}$ & 244 & pink collar & China & 43 & 100 & CS & $91.3 \%$ & $\begin{array}{l}W+C(D A \\
S D)+S(C, S S)\end{array}$ & + \\
\hline $\begin{array}{l}\text { Hooftman, } \\
2009\left[56^{*}\right]\end{array}$ & 1259 & $\begin{array}{l}\text { mixed } \\
\text { collar }\end{array}$ & Netherlands & 36 & 31 & $P$ & $\begin{array}{l}87 \% \text { (baseline) } 92 \% \text { (for at least one } \\
\text { follow-up) }\end{array}$ & $\begin{array}{l}W+C(S D)+S \\
(C, S S)\end{array}$ & + \\
\hline $\begin{array}{l}\text { Hoogendoorn, } \\
2001\left[57^{*}\right]\end{array}$ & 861 & $\begin{array}{l}\text { mixed } \\
\text { collar }\end{array}$ & Netherlands & 36 & 30 & $P$ & 87\% (baseline) & $\begin{array}{l}W+C(D A \\
S D)+S(C, S S)\end{array}$ & + \\
\hline $\begin{array}{l}\text { Latza, } 2002 \\
{\left[58^{*}\right]}\end{array}$ & 488 & blue collar & Germany & 32 & 0 & $P$ & $\begin{array}{l}\text { 85.5\% (follow-up) [for baseline not } \\
\text { determined] }\end{array}$ & $\begin{array}{l}W+C(D A)+ \\
S\end{array}$ & + \\
\hline $\begin{array}{l}\text { Matsudaira, } \\
2012\left[59^{*}\right]\end{array}$ & 836 & $\begin{array}{l}\text { mixed } \\
\text { collar }\end{array}$ & Japan & 44 & 12 & $P$ & $\begin{array}{l}86.5 \% \text { (baseline) } 71.6 \% \text { (follow-up 1) } \\
84.0 \% \text { (follow-up 2) }\end{array}$ & $\begin{array}{l}W+C(D A \\
S D)+S(C, S S)\end{array}$ & + \\
\hline $\begin{array}{l}\text { Matsudaira, } \\
2015\left[60^{*}\right]\end{array}$ & 171 & blue collar & Japan & 42 & 29 & $P$ & 86.5\% (baseline) 71.8\% (follow-up) & $\mathrm{R}$ & ++ \\
\hline $\begin{array}{l}\text { Melloh, } 2013 \\
{\left[61^{*}\right]}\end{array}$ & 169 & $\begin{array}{l}\text { mixed } \\
\text { collar }\end{array}$ & $\begin{array}{l}\text { New } \\
\text { Zealand }\end{array}$ & 36 & 62 & $P$ & 74\% (baseline) 54\% (across all follow-ups) & $W+S$ & - \\
\hline $\begin{array}{l}\text { Messing, } 2009 \\
{\left[62^{*}\right]}\end{array}$ & 7757 & $\begin{array}{l}\text { mixed } \\
\text { collar }\end{array}$ & Canada & 36 & 42 & CS & $\begin{array}{l}82 \% / 84 \% \text { (interviewer-administered / } \\
\text { self-administered questionnaire) }\end{array}$ & W & - \\
\hline $\begin{array}{l}\text { Tsigonia, } 2009 \\
{\left[63^{*}\right]}\end{array}$ & 102 & pink collar & Greece & 38 & 93 & CS & $90 \%$ & $\begin{array}{l}W+C(S D)+S \\
(C)\end{array}$ & + \\
\hline $\begin{array}{l}\text { van den } \\
\text { Heuvel, } 2004 \\
{\left[64^{*}\right]}\end{array}$ & 787 & $\begin{array}{l}\text { mixed } \\
\text { collar }\end{array}$ & Netherlands & 36 & 31 & $P$ & 87\% (baseline) & $\begin{array}{l}W+C(D A \\
S D)+S(C, S S)\end{array}$ & + \\
\hline $\begin{array}{l}\text { Violante, } 2004 \\
{\left[65^{*}\right]}\end{array}$ & 858 & pink collar & Italy & 36 & 100 & CS & $95.2 \%$ & $W+R$ & - \\
\hline
\end{tabular}

$N$ Sample size, Age Mean age in sample, Females Percentage of females in sample, $P$ Prospective, CS Cross-sectional; Exposures assessed: $W$ Workload, $C$ Control, $D A$ Decision authority, SD Skill discretion, $S$ Social support, $C$ Colleague, SS Supervisor, $R$ Reward, $++=$ high, $+=$ medium, $-=$ low

\section{Sensitivity analyses}

We also checked for potential outliers across the studies. However, for none of the examined relationships we found evidence for such extreme deviations of single effect sizes (all primary study ORs between $\pm 3 S D$ from the mean).

With regard to potential time trends, we conducted a series of cumulative meta-analyses according to Borenstein et al. [46]. For this reason, we sorted and entered the studies effect sizes chronologically for pooling. The forest plots (not shown here) displayed a rather consistent narrowing and stabilization of pooled effect size estimates and their confidence intervals. This means that time of publication per se does not affect the interpretation of our results.

We further examined how significance of the pooled effect size estimates changes if certain studies would be excluded from the analysis (one-study-removed procedure described by [46]). For workload, control, and social support no shift in effect sizes was found. However, with regard to small sample of studies considering reward and CLBP we note that the reported protective effect $(O R<1)$ in the study of Violante et al. [65*] was significant while the effect reported by Matsudaira et al. [60*] was not. 
Table 2 Meta-analytic results for relationships between psychosocial work factors and CLBP

\begin{tabular}{|c|c|c|c|c|c|c|c|c|c|c|}
\hline \multirow[t]{2}{*}{ Psychosocial factors } & \multirow[t]{2}{*}{ k } & \multirow[t]{2}{*}{$N$} & \multirow[t]{2}{*}{$\mathrm{OR}$} & \multicolumn{2}{|c|}{$95 \% \mathrm{Cl}$} & \multicolumn{2}{|c|}{$95 \% \mathrm{PI}$} & \multirow[t]{2}{*}{$Q(k-1)$} & \multirow[t]{2}{*}{$p(Q)$} & \multirow[t]{2}{*}{$P^{2}$} \\
\hline & & & & $L L$ & UL & $L$ & UL & & & \\
\hline Workload & 14 & 14,964 & 1.32 & 1.20 & 1.46 & 1.20 & 1.46 & 13.04 & .445 & 0.3 \\
\hline \multicolumn{11}{|l|}{ Job Control } \\
\hline Combined & 13 & 7635 & 0.81 & 0.70 & 0.94 & 0.59 & 1.34 & 38.56 & $<.001$ & 68.9 \\
\hline Decision Authority & 8 & 4649 & 0.72 & 0.59 & 0.87 & 0.39 & 1.32 & 25.98 & .001 & 73.1 \\
\hline Skill Discretion & 7 & 4868 & 0.85 & 0.70 & 1.04 & 0.46 & 1.56 & 19.91 & .003 & 69.9 \\
\hline \multicolumn{11}{|l|}{ Social Support } \\
\hline Combined & 12 & 9043 & 0.77 & 0.65 & 0.90 & 0.46 & 1.28 & 32.09 & .001 & 65.7 \\
\hline Colleague & 7 & 4975 & 0.75 & 0.61 & 0.93 & 0.40 & 1.40 & 17.88 & .007 & 66.4 \\
\hline Supervisor & 8 & 8099 & 0.78 & 0.70 & 0.86 & 0.68 & 0.89 & 6.90 & .440 & $<.01$ \\
\hline Reward & 2 & 1029 & 0.67 & 0.15 & 3.05 & - & - & 6.87 & .009 & 85.4 \\
\hline
\end{tabular}

$k$ Number of included studies, $N$ Cumulated sample size, OR Mean sample size-weighted (pooled) odds ratio, LL Lower limit, UL Upper limit, CI Confidence interval, $P$ I Prediction interval, Q Q-Statistics for heterogeneity and corresponding $p(Q)$-values, $I^{2}$ Index of heterogeneity $I^{2}$ (percent)

\section{Publication bias}

A potential publication bias might affect the accuracy of meta-analytic results [46]. We investigated such a systematic neglect of study results as described below. First, funnel plots (can be requested from the authors) did not indicate an asymmetric distribution of effect sizes and standard errors. However, funnel plot analysis is largely based on subjective judgement. Therefore, Table 6 shows some statistical procedures for detecting a publication bias. We conducted a trim-and-fill analysis which simulates pooled effect size estimates under the assumption that (hypothetic) effect sizes are included that bring

Table 3 Results of meta-analytic moderator analyses for workload, job control (combined) and job control (decision authority)

\begin{tabular}{|c|c|c|c|c|c|c|c|c|c|c|c|c|c|c|c|c|c|c|}
\hline & \multicolumn{6}{|c|}{ Workload } & \multicolumn{6}{|c|}{ Job control-combined } & \multicolumn{6}{|c|}{ Job control-decision authority } \\
\hline & $\bar{k}$ & OR & LL & $U L$ & $P^{2}$ & z-Test & $\bar{k}$ & OR & LL & $U L$ & $p^{2}$ & z-Test & k & OR & LL & UL & $P^{2}$ & $z$-Test \\
\hline \multicolumn{19}{|l|}{ Study Design } \\
\hline Cross-sectional & 7 & 1.38 & 1.22 & 1.56 & 0.0 & \multirow[t]{2}{*}{$p=.332$} & 6 & 0.88 & 0.70 & 1.10 & 36.1 & \multirow[t]{2}{*}{$p=.385$} & 4 & 0.80 & 0.63 & 1.01 & 52.1 & \multirow[t]{2}{*}{$p=.164$} \\
\hline Prospective & 7 & 1.25 & 1.07 & 1.45 & 2.4 & & 7 & 0.77 & 0.63 & 0.93 & 77.2 & & 4 & 0.63 & 0.49 & 0.80 & 68.1 & \\
\hline \multicolumn{19}{|l|}{ Occupation } \\
\hline Blue & 3 & 1.63 & 1.16 & 2.28 & 0.0 & \multirow[t]{3}{*}{$p=.441$} & 3 & 0.84 & 0.58 & 1.21 & 0.0 & \multirow[t]{3}{*}{$p=.832$} & 1 & 0.72 & 0.44 & 1.19 & 0.0 & \multirow[t]{3}{*}{$p=.343$} \\
\hline Mixed & 6 & 1.28 & 1.12 & 1.47 & 19.9 & & 5 & 0.77 & 0.61 & 0.97 & 84.7 & & 3 & 0.60 & 0.45 & 0.81 & 74.2 & \\
\hline Pink & 5 & 1.32 & 1.13 & 1.54 & 19.0 & & 5 & 0.85 & 0.66 & 1.11 & 46.9 & & 4 & 0.80 & 0.63 & 1.02 & 52.1 & \\
\hline \multicolumn{19}{|l|}{ Study Quality } \\
\hline High & - & & & & & \multirow[t]{3}{*}{$p=.675$} & - & & & & & \multirow[t]{3}{*}{$p=.548$} & - & & & & & \multirow[t]{3}{*}{$p=.265$} \\
\hline Medium & 11 & 1.30 & 1.15 & 1.48 & 6.3 & & 11 & 0.82 & 0.70 & 0.97 & 69.9 & & 7 & 0.74 & 0.61 & 0.91 & 74.1 & \\
\hline Low & 3 & 1.37 & 1.14 & 1.64 & 7.9 & & 2 & 0.72 & 0.47 & 1.10 & 79.2 & & 1 & 0.51 & 0.28 & 0.95 & 0.0 & \\
\hline \multicolumn{19}{|l|}{ Country } \\
\hline Asia & 2 & 1.38 & 1.04 & 1.83 & 0.0 & \multirow[t]{4}{*}{$p=.946$} & 2 & 0.89 & 0.70 & 1.14 & 0.0 & \multirow[t]{4}{*}{$p<.001$} & 1 & 0.81 & 0.63 & 1.04 & 0.0 & \multirow[t]{4}{*}{$p=.003$} \\
\hline Australia/NZ & 1 & 1.20 & 0.78 & 1.84 & 0.0 & & - & & & & & & - & & & & & \\
\hline Europe & 9 & 1.31 & 1.11 & 1.54 & 17.1 & & 9 & 0.88 & 0.80 & 0.96 & 7.4 & & 5 & 0.80 & 0.67 & 0.95 & 39.8 & \\
\hline Northern America & 2 & 1.37 & 1.02 & 1.86 & 51.5 & & 2 & 0.49 & 0.41 & 0.60 & 0.0 & & 2 & 0.47 & 0.36 & 0.62 & 0.0 & \\
\hline Exposure (months) & 7 & \multicolumn{4}{|c|}{$P E=.004, S E=.011$} & $p=.724$ & 7 & \multicolumn{4}{|c|}{$P E=.001, S E=.002$} & $p=.346$ & 4 & \multicolumn{4}{|c|}{$P E=-.004, S E=.013$} & $p=.766$ \\
\hline Year of Publication & 14 & \multicolumn{4}{|c|}{$P E=-.012, S E=.015$} & $p=.419$ & 13 & \multicolumn{4}{|c|}{$P E=-.035, S E=.017$} & $p=.039$ & 8 & \multicolumn{4}{|c|}{$P E=-.056, S E=.023$} & $p=.014$ \\
\hline Sample Size & 14 & \multicolumn{4}{|c|}{$P E<.001, S E<.001$} & $p=.335$ & 13 & \multicolumn{4}{|c|}{$P E<.001, S E<.001$} & $p=.980$ & 8 & \multicolumn{4}{|c|}{$P E<-.001, S E<.001$} & $p=.503$ \\
\hline Mean Age & 14 & $P E=-$ & 004,5 & $=.014$ & & $p=.798$ & 13 & $P E=-$ & $029, S$ & $=.013$ & & $p=.028$ & 8 & $P E=-$ & $023, S$ & $=.016$ & & $p=.149$ \\
\hline Females (\%) & 14 & $P E=-$ & $001, s$ & $=.001$ & & $p=.645$ & 13 & $P E=.0$ & $02, S E$ & .002 & & $p=.364$ & 8 & $P E=$. & $03, S E$ & .002 & & $p=.111$ \\
\hline
\end{tabular}

$k$ Number of included studies, OR Mean sample size-weighted (pooled) odds ratio, $L L$ Lower limit of $95 \%$ confidence interval (Cl), UL Upper limit of $95 \% \mathrm{Cl}, l^{2}$ Index of heterogeneity $I^{2}$ (in percent), PE Point estimate of predictor from meta-regression (and corresponding standard error SE) 
Table 4 Results of meta-analytic moderator analyses for job control (skill discretion) and social support (combined and colleagues)

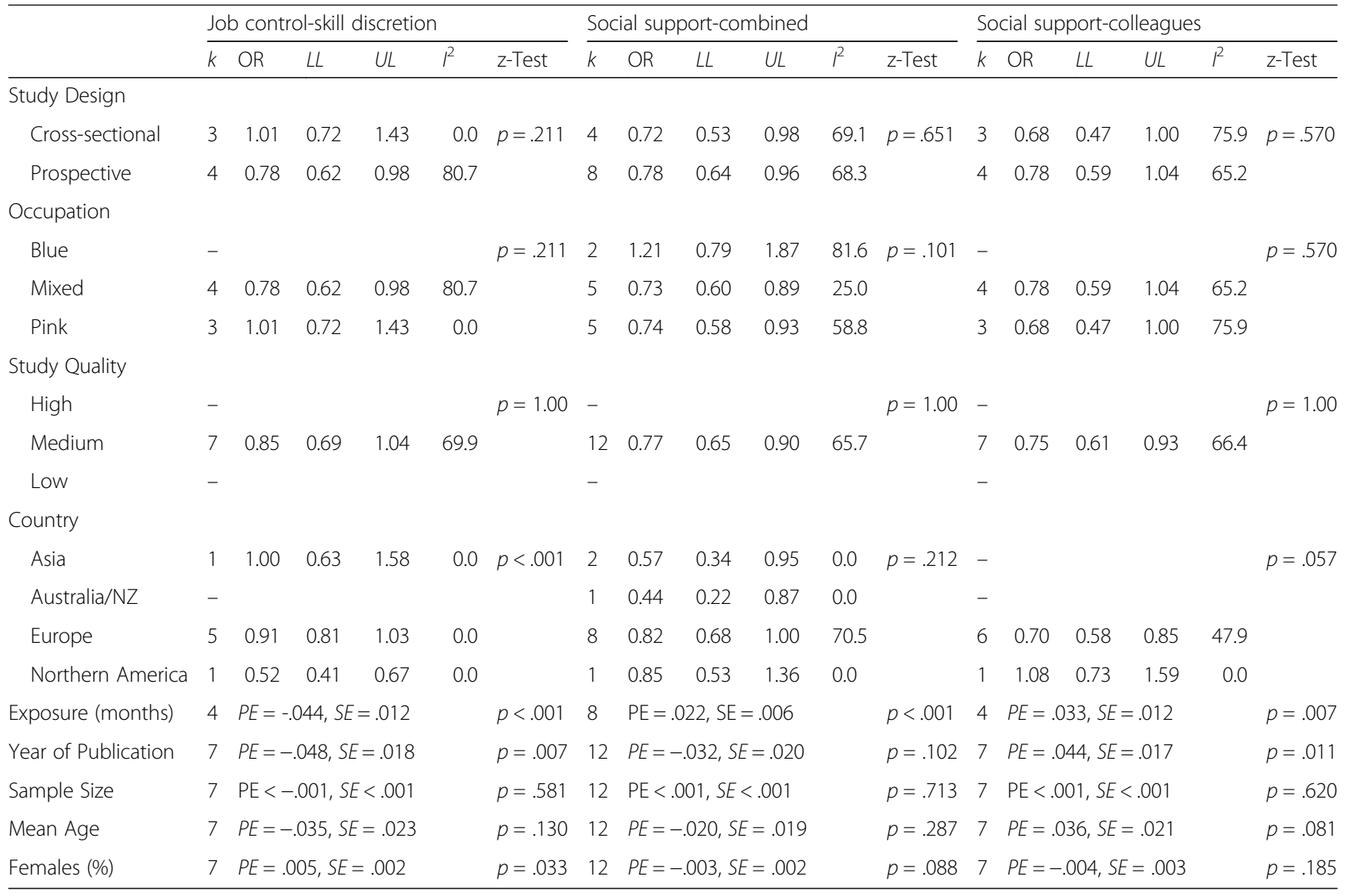

$k$ Number of included studies, OR Mean sample size-weighted (pooled) odds ratio, LL Lower limit of $95 \%$ confidence (precision) interval (CI), UL Upper limit of $95 \%$ $\mathrm{Cl}, I^{2}$ Index of heterogeneity $I^{2}$ (percent), PE Point estimate of predictor from meta-regression (and corresponding standard error SE)

their total distribution to (nearly) perfect symmetry in the funnel plot. While mean pooled effect size estimates and their significance hardly changed for workload, job control (combined and decision authority), and social support (combined, colleagues, supervisor), the simulation yielded stronger protective effects on CLBP for skill discretion $(\mathrm{OR}=0.77$ instead of $\mathrm{OR}=0.85$ from this sample of studies) which was now significant. We further investigated asymmetric effect size distribution with a test of intercepts by Egger. However, intercepts were not significant. Thus, asymmetry was not indicated. In sum, our analyses might indicate a potential (small) publication bias for relationships between skill discretion as dimension of job control and CLBP revealing that our results might underestimate potential true effect size estimates.

\section{Discussion}

Using data from 18 studies with 19,572 employees in total, this systematic review and meta-analysis examined relationships between psychosocial work factors from the AW model [32] and CLBP lasting 3 months and longer [19]. Our results suggest an overlap between psychosocial workplace factors associated with low back pain in general $[25,27]$ and those associated with CLBP: Workload, job control, and social support. Therefore, the proposed yellow flags for CLBP should be reassessed. However, psychosocial factors that Leiter and Maslach [32] suggested as job resources against work stress developing from current changes in the working world, for instance, high fairness and a fit between personal and organizational values, have been widely neglected in relation to CLBP. Future research should strengthen research in these areas to get a more comprehensive and complementary view on how different work-related psychosocial risk factors affect the longterm development of musculoskeletal problems.

\section{AW factors and CLBP}

The results of our review and meta-analysis supported that well-known psychosocial work factors such as workload, job control, and social support significantly relate to CLBP. More specifically, high workload increases the risk whereas high job control reduces the risk for developing CLBP. However, the latter association was supported only for the combined measure of job control and for decision authority alone, but not for skill discretion. High social support from colleagues and 
Table 5 Results of meta-analytic moderator analyses for social support from supervisor

\begin{tabular}{|c|c|c|c|c|c|c|}
\hline & k & OR & LL & $U L$ & $P^{2}$ & z-Test \\
\hline \multicolumn{7}{|l|}{ Study Design } \\
\hline Cross-sectional & 3 & 0.84 & 0.69 & 1.02 & 48.9 & \multirow[t]{2}{*}{$p=.380$} \\
\hline Prospective & 5 & 0.76 & 0.67 & 0.86 & 0.0 & \\
\hline \multicolumn{7}{|l|}{ Occupation } \\
\hline Blue & - & & & & & \multirow[t]{3}{*}{$p=.497$} \\
\hline Mixed & 4 & 0.76 & 0.66 & 0.87 & 0.0 & \\
\hline Pink & 4 & 0.82 & 0.68 & 0.98 & 28.4 & \\
\hline \multicolumn{7}{|l|}{ Study Quality } \\
\hline High & - & & & & & \multirow[t]{3}{*}{$p=1.00$} \\
\hline Medium & 8 & 0.78 & 0.70 & 0.86 & 0.0 & \\
\hline Low & - & & & & & \\
\hline \multicolumn{7}{|l|}{ Country } \\
\hline Asia & 1 & 0.62 & 0.42 & 0.91 & 0.0 & \multirow[t]{4}{*}{$p=.155$} \\
\hline Australia/NZ & - & & & & & \\
\hline Europe & 6 & 0.82 & 0.73 & 0.93 & 0.0 & \\
\hline Northern America & 1 & 0.67 & 0.52 & 0.85 & 0.0 & \\
\hline Exposure (months) & 5 & \multicolumn{3}{|c|}{$P E=-.009, S E=.010$} & & $p=.364$ \\
\hline Year of Publication & 8 & \multicolumn{3}{|c|}{$P E=-.029, S E=.017$} & & $p=.083$ \\
\hline Sample Size & 8 & \multicolumn{3}{|c|}{$P E<-.001, S E<.001$} & & $p=.751$ \\
\hline Mean Age & 8 & \multicolumn{3}{|c|}{$P E=-.019, S E=.014$} & & $p=.189$ \\
\hline Females (\%) & 8 & \multicolumn{3}{|c|}{$P E=.001, S E=.002$} & & $p=.494$ \\
\hline
\end{tabular}

$k$ Number of included studies, OR Mean sample size-weighted (pooled) odds ratio, LL Lower limit of $95 \%$ confidence (precision) interval (CI), UL Upper limit of $95 \% \mathrm{Cl}, I^{2}$ Index of heterogeneity $I^{2}$ (percent), PE Point estimate of predictor from meta-regression (and corresponding standard error $\mathrm{SE}$ )

supervisors also proved to be a resource that prevents or reduces the risks for CLBP. Our findings contribute to the literature in at least two ways. First, our results extend findings from other meta-analyses in this field of research revealing that high work-related psychosocial risk factors such as high workload, low job control, and low social support not only increase the risk for current musculoskeletal symptoms [25, 27] but also drive the development of CLBP in a long run. Second, our results also bolster theoretical assumptions from the JobDemands-Control-Support model (JDCS [21];) that these three central work factors not only affect employees' well-being (see [31] for a review) but also relate to physical strain symptoms. Theoretical models on how psychosocial work stressors affect the development of musculoskeletal strain reactions assume two paths (see [41] for an integration of study results): (a) a physical one via increased load at work and (b) a psychophysiological one via increased muscle tension, prolonged activation of motor units, and changes in blood supply and anabolic activity. Our purpose was not to uncover the exact mechanisms of CLPB. However, this is an important task for future reviews because such information might be helpful in developing preventive measures at the worksite.

The purpose of the AW model [32] was to extend the traditional JDCS model by including new and theoretically-based work factors with a further potential to reduce upcoming strain-reactions from work. One of those, reward, was considered in two studies but the pooled effect size for relationships to CLBP was not significant here. The results of the sensitivity analysis also showed inconsistent associations. We note that such small sized and heterogeneous effects might also be due to ignoring potential moderators such as the level of workload and the individuals' tendency to work more than expected [34]. These moderators could strengthen the risks of low reward for CLBP. However, such moderating effects were not investigated in our selected sample of studies calling for more research efforts in future. This also concerns the impact of psychosocial risk factor patterns. For instance, Lang et al. [25] and Hauke et al. [41] found some initial support that the risks for back symptoms are significantly increased under high strain jobs, which means a combination of low control and high demands.

We found no studies investigating the relationships between CLBP and fairness and values. Associations between workplace injustice, which means a lack of fairness, and backaches have been reported [66, 67]. However, fairness and values are the motivating connection between the worker and the workplace, which goes beyond the utilitarian exchange of time for money or career. Due to globalization and digitalization those psychosocial work factors become increasingly important [30] and on their relation to physical well-being should be more concentrated in the future.

In sum, we found that research on work-related factors and CLBP has mainly stressed on the role of task characteristics (workload, control) and interpersonal characteristics (support). However, in line with the AW model it might be valuable to extend this view in future research to the role of organizational variables (i.e., reward, values, fairness).

\section{Moderator analysis}

For most of the reported relationships between psychosocial risk factors and CLBP heterogeneity of effect sizes between studies was indicated. Therefore, average relationships should be interpreted with caution. In turn, we conducted a series of moderator analyses to get more insights on factors explaining such between-study variance.

We found a moderating role of samples' mean age for the relationship between job control and CLBP. Similarly, Zacher and Schmitt [68] point to interaction effects 


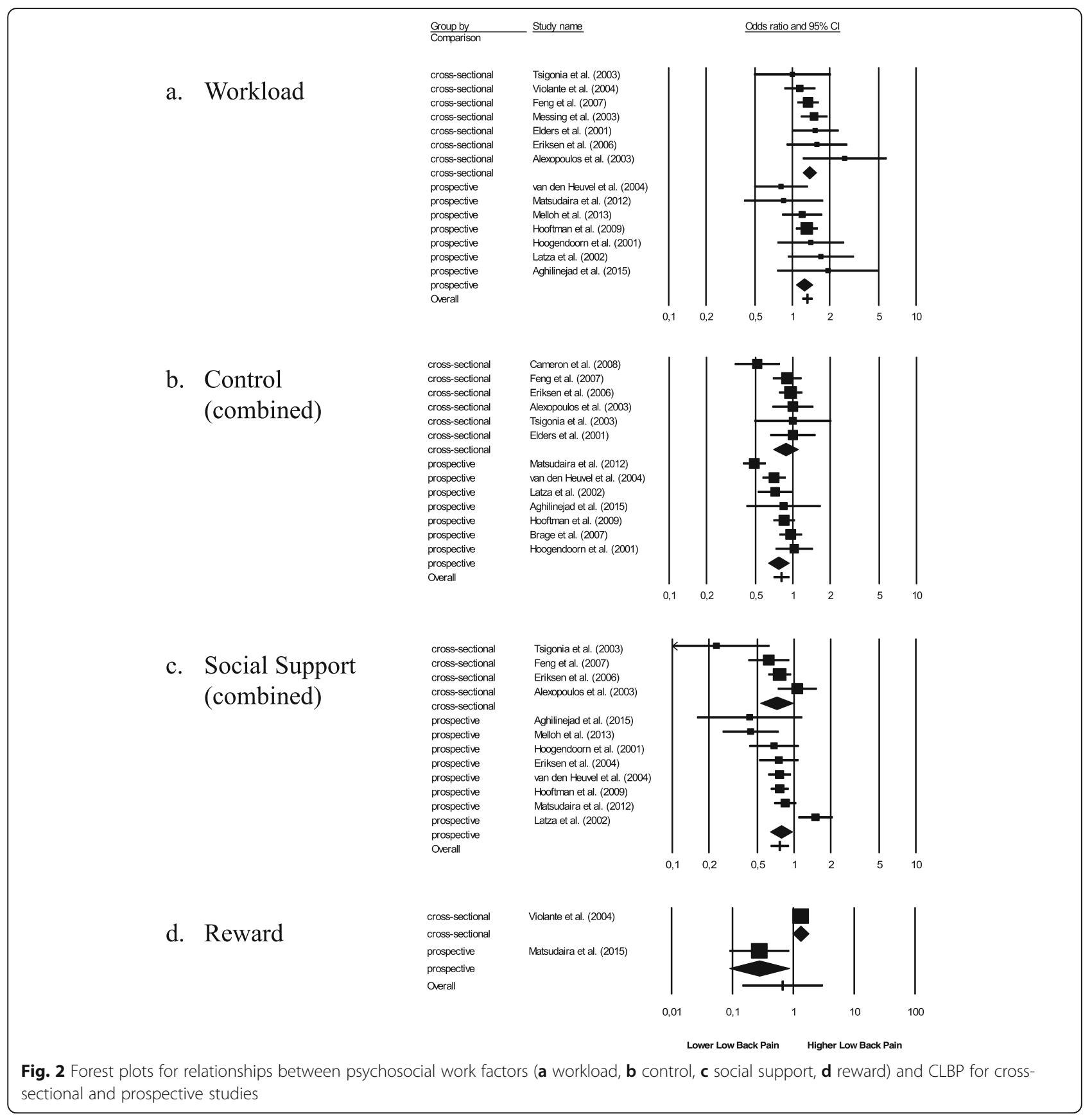

of work related factors and age on occupational wellbeing. One explanation could be that older workers in contrast to younger ones have higher emotional competencies that are helpful in dealing with such workplace stressors. This concerns, for instance, the regulation of own emotions and understanding others' emotions which was as supported by a recent systematic review [52].

Skill discretion did not significantly correlate with CLBP. However, we found exposure duration and sex distribution as potential moderator variables affecting this relationship. First, it is possible that employees actively shape their working conditions in sense of job crafting which, in turn, reduces CLBP. Job crafting goes beyond the more traditional 'top-down' concepts of work design and describes the active redesign of one's own work by the employees themselves as a bottom-up process $[69,70]$. Through job crafting employees regain control and influence at work [70]. Second, these results further suggest that it is necessary to keep such demographic variables as sex and age (as we discussed above) not only as confounders of CLBP but also as potential 
Table 6 Results of analyses for publication bias

\begin{tabular}{|c|c|c|c|c|c|c|c|c|}
\hline \multirow[t]{3}{*}{ Psychosocial factors } & \multirow{3}{*}{$\begin{array}{l}= \\
k\end{array}$} & \multicolumn{4}{|c|}{ Trim \& fill (Duval \& Tweedie) } & \multicolumn{3}{|c|}{$\underline{\text { Egger test }}$} \\
\hline & & \multirow[t]{2}{*}{$k(\mathrm{t})$} & \multirow[t]{2}{*}{$O R(\mathrm{t})$} & \multicolumn{2}{|c|}{$95 \% \mathrm{Cl}$} & \multirow[t]{2}{*}{$b$} & \multicolumn{2}{|l|}{$95 \% \mathrm{Cl}$} \\
\hline & & & & LL & UL & & LL & UL \\
\hline Workload & 14 & 1 & 1.31 & 1.16 & 1.46 & 0.13 & -1.15 & 1.42 \\
\hline \multicolumn{9}{|l|}{ Job Control } \\
\hline Combined & 13 & 2 & 0.79 & 0.68 & 0.91 & 0.68 & -2.58 & 3.93 \\
\hline Decision Authority & 8 & 1 & 0.70 & 0.58 & 0.84 & -0.52 & -5.13 & 4.08 \\
\hline Skill Discretion & 7 & 2 & 0.77 & 0.64 & 0.93 & 0.85 & -5.25 & 6.95 \\
\hline \multicolumn{9}{|l|}{ Social Support } \\
\hline Combined & 12 & 4 & 0.85 & 0.72 & 1.01 & -1.32 & -3.77 & 1.12 \\
\hline Colleague & 7 & 1 & 0.79 & 0.62 & 0.99 & -1.84 & -6.13 & 2.45 \\
\hline Supervisor & 8 & 0 & 0.78 & 0.70 & 0.86 & 0.52 & -2.49 & 3.54 \\
\hline
\end{tabular}

$k$ Number of included studies, $k(t)$ Number of trimmed studies, OR(t) Estimated OR after including trimmed studies, $C l$ Confidence interval, $L L$ Lower limit, UL Upper limit, $b$ Regression intercept

moderating variables. Therefore, future studies should compare adjusted models with moderator models (e.g., stratified models) when investigating relationships between psychosocial risk factors and CLBP.

\section{Limitations}

Our review is not without limitations. First, we conducted an extensive literature research of studies. However, the number of available studies for data aggregation was limited. Although the number of studies is similar to other reviews in this research $[25,27,41]$, the small number of cases affects the precision of effect size estimates and also the possibility to conduct moderator analyses because of low statistical power. In addition, we note that we were not able to adjust pooled effect size estimates for unreliability and 'artificial' dichotomization of variables as information was missing in the studies [46]. Consequently, our results most likely represent rather conservative estimates of true effects. Future research in this domain should report reliability estimates of measures and should use the full-scale range instead of dichotomizing variables.

Second, we included articles from published peerreviewed journals and only articles in German or English language. By chance, these studies primarily examined Caucasian populations from Europe. Therefore, pooled effect size estimates and heterogeneity of effect sizes might change when including samples from other countries and, in addition, when integrating data from unpublished studies. However, with the relationship between skill discretion and CLBP as an exception, we found only weak evidence for a possible publication bias [46]. In addition, simulation analyses revealed only a minor impact of such a bias for the presented average effects. Thus, the reported pooled effect size estimates seem to be relatively robust. Nevertheless, future metaanalyses might extend the scope of literature search.

Finally, the low to medium quality of included studies might have biased our results. The most common problem involves an unspecific assessment of the outcome. Although CLPB was clearly defined according to our inclusion criteria (pain in the lumbar region lasting for 3 month or longer), many studies did not apply such a measure (see e.g. $\left[60^{*}, 61,71^{*}\right]$ ). One reason might be a lack of agreement about the definition of CLBP $[16,17]$ and, in turn, no consistent use of measures. In addition, some studies did not report the reliability of the instruments to measure psychosocial stressors or main characteristics of the study population. Also, adjustment of confounders varied across the studies. However, we always used effect sizes for pooling that were at least adjusted for demographic variables, also to strengthen their comparability. Moreover, reported pooled effect size estimates were comparable in studies using prospective designs with higher quality and, in addition, we found no evidence that methodological quality of studies was a moderator affecting the reported effect size estimates. In sum, we conclude that although our review of literature calls for more high quality studies in this research, study quality is not a variable explaining the results reported here.

\section{Research implications}

In view of the changes within the current working world, job exposures that shape the exchange and interplay between organization and employee, for instance, reward, fairness, and values, are expected to become more important in maintaining health in general and preventing CLBP in particular [72, 73]. Consequently, there is a need for future research 
investigating those constructs more specifically. Additionally, we recommend including all of the AW factors [32] that are workload, control, support, reward, fairness, and values. Keeping up this rationale, it would be possible to investigate combined additive and interactive effects of these psychosocial workrelated factors over and above the assumptions from the JDCS model $[31,74]$ and the effort-reward imbalance model [34].

An enormous challenge in preparing the systematic review was the identification of studies using an accurate and rigorous definition of CLBP. We defined CLBP as unspecific LBP lasting for 3 month or longer. During literature search, we noted that there is a substantial lack in studies investigating the association between psychosocial work factors and CLBP following this definition. Future research should use a more consistent and rigorous definition of CLBP, apply appropriate (valid and reliable) measures for CLBP in order to improve consistency of results and to allow a comparative analysis. Meucci and colleagues [75] suggested a minimal definition of CLBP that includes a precise description of the anatomical area, the pain duration, and level of CLBP induced limitations in general daily activities. Moreover, to increase the validity of diagnosis the assessment of CLBP by interviews and by medical examinations should be preferred in contrast to self-report questionnaires.

Although we found a number of prospective studies that could be included in our review, future research should apply high quality randomized and longitudinal case-control studies as well as intervention studies more often. Such designs allow investigating causal interference of relationships between work exposures and CLBP more strongly. Therefore, future research should investigate psychosocial risk factors of the AW model in combination when exploring antecedents of CLBP.

\section{Practical implications}

In view of the rising burden and associated high costs of CLBP [76-78] for the individuals (e.g., reduced life activities, impaired well- being), for the employers (e.g., lower work performance, higher absence rates from work), and for the society (e.g., expenses of health care services and social welfare system) this meta-analysis yields important implications for public health and human resource management. In particular, the chronic state of back pain constitutes a unique clinical syndrome [1] representing a great challenge for interventions [79]. Our results suggest that psychosocial job exposures (workload, control and social support) are not only associated with a higher risk for lower back pain (e.g. [25]) but also with a higher risk that this becomes chronic. Therefore, a reduction of those stressors and the design of healthy job exposures are required for CLBP prevention.

Using a stepwise approach, first, potential risk factors at work have to be assessed with valid instruments, for instance, by self-report [35, 80] or by workplace observation [81, 82]. Second, organizational-level interventions designed to change and to optimize those psychosocial factors (e.g. task restructuring, increasing work control or the level of participation) need to be implemented. More specifically, other research found that if the involvement of employees during interventions is high, measurements focusing on the design of 'healthy' workplaces are more successful $[83,84]$. For instance, involvement can be increased bottom-up if employees develop contextspecific solutions in cooperation, prepare action plans targeting the improvement of their health and wellbeing, and, in turn, implement and evaluate these measures. There might be situations where a reduction of psychosocial stressors is hardly possible (e.g., high workload because of absence-related understaffing). Therefore, according to our results, it is necessary to strengthen potential job resources with the power to reduce adverse (physical) effects of high job demands [85]. This concerns task-level and interpersonal-level work factors such as time and method control and opportunities for social support but also time to recover from work [86]. For instance, a recent meta-analysis showed that even paid withinshift breaks reduce employees' physical discomfort and increase their well-being and task-performance [87]. Moreover, increasing employees' psychological detachment from work seems to be a helpful recovery process for preventing physical discomfort and back pain $[86,88]$. In sum, participatory and organizational-focused interventions could serve as an important complement to the widely used individual-level measures $[89,90]$ to reduce the risk of CLBP.

\section{Conclusion}

In this meta-analysis, we found substantial evidence that psychosocial work factors such as high workload, low job control, and low social support drive risks in developing CLBP. Although our reported effect sizes are rather conservative estimates, undermining potential true effects, the results revealed robust evidence of an association between exposures to work-related psychosocial risk factors and CLBP, even in prospective studies. However, after reviewing the existing literature we also found several challenges that need to be considered in future studies when trying to explain how CLBP is shaped, affected, and to be prevented. 


\section{Appendix 1}

\section{Search string}

Study population (sensitive string according to Mattioli, 2010 [91]

(occupational diseases [MH] OR occupational exposure [MH] OR occupational exposure* [TW] OR "occupational health" OR "occupational medicine" OR workrelated OR working environment [TW] OR at work [TW] OR work environment [TW] OR occupations $[\mathrm{MH}]$ OR work $[\mathrm{MH}]$ OR workplace* $[\mathrm{TW}]$ OR workload OR occupation* OR worke* OR work place* [TW] OR work site* [TW] OR job* [TW] OR occupational groups $[\mathrm{MH}]$ OR employment OR worksite* OR industry) AND

\section{Outcome}

((back pain) OR (low back pain) OR (chronic back pain) OR (chronic* AND back pain) OR (back disorder) OR (back complaints) OR (musculoskeletal disorder $^{*}$ ) OR (musculoskeletal disease*)) AND

\section{Exposure $^{1}$}

((workload) OR (workload) OR (work load[MeSH Terms])) OR (mental workload) OR (mental load) OR (emotional load) OR (occupational workload) OR (physical workload) OR (work demand) OR (job strain) OR (intensity of labour) OR (intensity of labor) OR (work environment)) OR (quantity of work) OR (job demand) OR (job load) OR (capacity) OR (time pressure)) OR ((work control) OR (decision latitude) OR (decision authority) OR (job control) OR (work autonomy) OR (job influence) OR (control[MeSH Terms]))OR (autonomy)) OR ((social support*) OR (support) OR (work conflict) OR (community)) OR ((reward) OR (payment) OR (effort-reward) OR (job opportunit*) OR (promotion prospects) OR (bonus)) OR ((fairness) OR (injustice) OR (justice) OR (equality) OR (unfairness)) OR ((value $\left.{ }^{*}\right)$ OR (cultur*) OR (standards) OR (ethic ${ }^{*}$ ) OR (ideal) OR (principle ${ }^{*}$ ) OR (belief*))

\footnotetext{
also emotional and physical demands/load for workload) during literature search as study measures sometimes mix different terms and definitions. This search approach is highly sensitive and results - as expected in a high number of recorded studies during PRISMAPhase 1 'Identification'.
}

${ }^{1}$ Note that we used a broad definition of the AWS (e.g.,

\section{Appendix 2}

Table $\mathbf{7}$ Items used to assess the quality of the included studies

\begin{tabular}{|c|c|}
\hline Section & In a well conducted study... \\
\hline $\begin{array}{l}\text { A. Study objective / } \\
\text { purpose }\end{array}$ & $\begin{array}{l}\text { (1) The study addresses an appropriate and } \\
\text { clearly stated question. }\end{array}$ \\
\hline $\begin{array}{l}\text { B. Study design/ } \\
\text { population }\end{array}$ & $\begin{array}{l}\text { (2) The population is selected from a total } \\
\text { population that is comparable in all aspects } \\
\text { other than the factor under investigation } \\
\text { (Positive if the main characteristics of the study } \\
\text { population are described; i.e., sampling frame } \\
\text { and distribution of the population by age and } \\
\text { sex). }\end{array}$ \\
\hline $\begin{array}{l}\text { C. Exposure } \\
\text { assessment }\end{array}$ & $\begin{array}{l}\text { (3) The study assesses and reports all relevant } \\
\text { exposures. } \\
\text { (4) The study assesses the exposure(s) } \\
\text { (psychosocial factors) with valid and reliable } \\
\text { instruments. }\end{array}$ \\
\hline $\begin{array}{l}\text { D. Outcome } \\
\text { assessment }\end{array}$ & $\begin{array}{l}\text { (5) The outcomes are clearly defined. } \\
\text { (6) The outcome is assessed with reliable and } \\
\text { valid instruments. } \\
\text { (7) The main potential confounders are } \\
\text { identified and taken into account in the study } \\
\text { design and data analysis (e.g., individual factors, } \\
\text { other psychosocial factors, physical factors). }\end{array}$ \\
\hline $\begin{array}{l}\text { E. Analysis and data } \\
\text { presentation }\end{array}$ & $\begin{array}{l}\text { (8) Effect sizes and their confidence intervals are } \\
\text { reported (or can be calculated from other data } \\
\text { reported). }\end{array}$ \\
\hline
\end{tabular}

Each item was coded as $1=$ 'positive' or $0=$ 'negative or unclear'. A total sum score was calculated indicating study quality

\section{Acknowledgments}

We thank our colleagues I Sagner, I Horvath-Kadner, M Melzer, and S S Lütke-Lanfer for their important support and discussion during study planning and literature review. We would like to thank our research students for help with literature search and study coding.

\section{Authors' contributions}

GB was responsible for study conception and design, contributed to the literature search and review process including quality assessment. AT managed the first draft of the manuscript, contributed to the literature search and review process including quality assessment. JW performed the data analysis. EO substantially contributed to study design. DD contributed to the literature search and review process, was responsible for the quality assessment. All authors were involved in writing and provided substantive feedback. Finally, all authors have read and approved the manuscript.

\section{Funding}

The Employers liability insurance association for health and welfare (BGW) funded this project. The sponsors had no influence on the planning, conduct, or reporting of this study from start to finish.

\section{Availability of data and materials}

Meta-analysis data and systematic materials can be requested from authors.

Ethics approval and consent to participate

Not applicable.

Consent for publication

All authors have agreed to the publication.

Competing interests

The authors declare that they have no competing interests. 


\section{Author details}

${ }^{1}$ Faculty of Health and Healthcare Sciences, Westsächsische Hochschule Zwickau, University of Applied Sciences, 08012 Zwickau, Germany. ${ }^{2}$ Faculty of Psychology, TU Dresden, Dresden, Germany. ${ }^{3}$ Division 3 Work and Health, Federal Institute of Occupational Health and Safety, Dresden, Germany. ${ }^{4}$ Department of Occupational Medicine, University Medical Center Schleswig-Holstein, Lübeck, Germany.

Received: 23 May 2019 Accepted: 12 September 2019

Published online: 25 October 2019

\section{References}

*Studies included in the meta-analysis are marked with an asterisk.

1. Waddell G. A new clinical model for the treatment of low back pain. Spine. 1987;12(7):632-44

2. Gatchel RJ, Peng YB, Peters ML, Fuchs PN, Turk DC. The biopsychosocial approach to chronic pain: scientific advances and future directions. Psychol Bull. 2007;133(4):581-624. https://doi.org/10.1037/0033-2909.133.4.581.

3. Wippert PM, Fliesser M, Krause M. Risk and protective factors in the clinical rehabilitation of chronic back pain. J Pain Res. 2017;10:1569-79. https://doi. org/10.2147/Jpr.S134976.

4. * Aghilinejad M, Tavakolifard N, Mortazavi SA, Kabir Mokamelkhah E, Sotudehmanesh A, Mortazavi SA. The effect of physical and psychosocial occupational factors on the chronicity of low back pain in the workers of Iranian metal industry: a cohort study. Med J Islam Repub Iran. 2015;29:242.

5. Ramond-Roquin A, Bouton C, Begue C, Petit A, Roquelaure Y, Huez JF. Psychosocial risk factors, interventions, and comorbidity in patients with non-specific low back pain in primary care: need for comprehensive and patient-centered care. Front Med. 2015;2:2-73. https://doi.org/10.3389/fmed. 2015.00073.

6. Matsudaira K, Konishi H, Miyoshi K, Isomura T, Inuzuka K. Potential risk factors of persistent low back pain developing from mild low back pain in urban Japanese workers. PLoS One. 2014;9(4):e93924. https://doi.org/10. 1371/journal.pone.0093924.

7. Sterud T, Tynes T. Work-related psychosocial and mechanical risk factors for low back pain: a 3-year follow-up study of the general working population in Norway. Occup Environ Med. 2013;70(5):296-302. https://doi.org/10.1136/ oemed-2012-101116.

8. Hoy D, Bain C, Williams G, March L, Brooks P, Blyth F, et al. A systematic review of the global prevalence of low back pain. Arthritis Rheum. 2012; 64(6):2028-37. https://doi.org/10.1002/art.34347.

9. Wippert PM, Puschmann AK, Driesslein D, Arampatzis A, Banzer W, Beck H, et al. Development of a risk stratification and prevention index for stratified care in chronic low back pain. Focus: yellow flags (MiSpEx network). Pain Rep. 2017;2(6):e623. https://doi.org/10.1097/PR9.0000000000000623.

10. Henschke N, Kamper SJ, Maher CG. The epidemiology and economic consequences of pain. Mayo Clin Proc. 2015;90(1):139-47. https://doi.org/10. 1016/j.mayocp.2014.09.010.

11. Maher C, Underwood M, Buchbinder R. Non-specific low back pain. Lancet. 2017;389(10070):736-47. https://doi.org/10.1016/s0140-6736(16)30970-9.

12. Chenot JF, Greitemann B, Kladny B, Petzke F, Pfingsten M, Schorr SG. Nonspecific low back pain. Dtsch Arztebl Int. 2017;114(51-52):883-90. https:// doi.org/10.3238/arztebl.2017.0883.

13. Snelgrove S, Edwards S, Liossi C. A longitudinal study of patients' experiences of chronic low back pain using interpretative phenomenological analysis: changes and consistencies. Psychol Health. 2013;28(2):121-38. https://doi.org/10.1080/08870446.2011.630734.

14. Waddell G, Burton AK. Occupational health guidelines for the management of low back pain at work: evidence review. Occup Med (Lond). 2001;51(2): 124-35.

15. Waddell G. Preventing incapacity in people with musculoskeletal disorders. Br Med Bull. 2006;77-78:55-69. https://doi.org/10.1093/bmb/ldl008.

16. Andersson GB. Epidemiological features of chronic low-back pain. Lancet. 1999;354(9178):581-5. https://doi.org/10.1016/S0140-6736(99)01312-4.

17. van Tulder M, Koes B, Bombardier C. Low back pain. Best Pract Res Clin Rheumatol. 2002;16(5):761-75. https://doi.org/10.1053/berh.2002.0267.

18. Rampersaud YR, Bidos A, Fanti C, Perruccio AV. The need for multidimensional stratification of chronic low back pain (LBP). Spine. 2017 42(22):E1318-E25. https://doi.org/10.1097/Brs.0000000000002237.
19. Merskey H, Bogduk N. Classification of chronic pain: descriptions of chronic pain syndromes and definitions of pain terms. 2nd ed. Seattle: International Association for the Study of Pain; 1994.

20. Huang GD, Feuerstein M, Sauter SL. Occupational stress and work-related upper extremity disorders: concepts and models. Am J Ind Med. 2002;41(5): 298-314. https://doi.org/10.1002/ajim.10045.

21. Johnson JV, Hall EM. Job strain, work place social support, and cardiovascular disease: a cross-sectional study of a random sample of the Swedish working population. Am J Public Health. 1988;78(10):1336-42.

22. Karasek RA. Job demands, job decision latitude, and mental strain -implications for job redesign. Adm Sci Q. 1979;24(2):285-308. https://doi. org/10.2307/2392498.

23. Janwantanakul P, Sitthipornvorakul E, Paksaichol A. Risk factors for the onset of nonspecific low back pain in office workers: a systematic review of prospective cohort studies. J Manip Physiol Ther. 2012;35(7):568-77. https:// doi.org/10.1016/j.jmpt.2012.07.008.

24. Canjuga M, Läubli T, Bauer GF. Can the job demand control model explain back and neck pain? Cross-sectional study in a representative sample of Swiss working population. Int J Ind Ergon. 2010;40(6):663-8. https://doi.org/ 10.1016/j.ergon.2010.08.003.

25. Lang J, Ochsmann E, Kraus T, Lang JWB. Psychosocial work stressors as antecedents of musculoskeletal problems: a systematic review and metaanalysis of stability-adjusted longitudinal studies. Soc Sci Med. 2012;75(7): 1163-74. https://doi.org/10.1016/j.socscimed.2012.04.015.

26. Elfering A, Semmer NK, Schade V, Grund S, Boos N. Supportive colleague, unsupportive supervisor: the role of provider-specific constellations of social support at work in the development of low back pain. J Occup Health Psychol. 2002;7(2):130-40. https://doi.org/10.1037//1076-8998.7.2.130.

27. Bernal D, Campos-Serna J, Tobias A, Vargas-Prada S, Benavides FG, Serra C. Work-related psychosocial risk factors and musculoskeletal disorders in hospital nurses and nursing aides: a systematic review and meta-analysis. Int J Nurs Stud. 2015;52(2):635-48. https://doi.org/10.1016/j.jinurstu.2014.11.003.

28. Pincus T, Burton AK, Vogel S, Field AP. A systematic review of psychological factors as predictors of chronicity/disability in prospective cohorts of low back pain. Spine. 2002;27(5):E109-E20.

29. World Trade Organization. World trade report 2018. Geneva: WTO; 2019.

30. d'Errico A, Viotti S, Baratti A, Mottura B, Barocelli AP, Tagna M, et al. Low back pain and associated presenteeism among hospital nursing staff. J Occup Health. 2013;55(4):276-83. https://doi.org/10.1539/joh.12-0261-OA.

31. Häusser JA, Mojzisch A, Niesel M, Schulz-Hardt S. Ten years on: a review of recent research on the job demand-control (-support) model and psychological well-being. Work Stress. 2010;24(1):1-35. https://doi.org/10. 1080/02678371003683747.

32. Leiter MP, Maslach C. Areas of worklife: a structured approach to organizational predictors of job burnout. In: Perrewé P, Ganster DC, editors. Research in occupational stress and well being. Oxford: Elsevier; 2004. p. 91-134.

33. Leiter MP, Maslach C. Six areas of worklife: a model of the organizational context of burnout. J Health Hum Serv Adm. 1999;21 (4):472-89.

34. Siegrist J, Klein D, Voigt KH. Linking sociological with physiological data: the model of effort-reward imbalance at work. Acta Physiol Scand. 1997;161:112-6.

35. Brom SS, Buruck G, Horváth I, Richter P, Leiter MP. Areas of worklife as predictors of occupational health - a validation study in two German samples. Burn Res. 2015;2(2-3):60-70. https://doi.org/10.1016/j.burn.2015.05.001.

36. Pohling R, Buruck $G$, Jungbauer KL, Leiter MP. Work-related factors of presenteeism: the mediating role of mental and physical health. J Occup Health Psychol. 2016;21(2):220-34. https://doi.org/10.1037/a0039670.

37. Maslach C, Schaufeli WB, Leiter MP. Job burnout. Annu Rev Psychol. 2001;52: 397-422. https://doi.org/10.1146/annurev.psych.52.1.397.

38. Melamed S. Burnout and risk of regional musculoskeletal pain-a prospective study of apparently healthy employed adults. Stress Health. 2009;25(4):31321. https://doi.org/10.1002/smi. 1265.

39. Langballe EM, Innstrand ST, Hagtvet KA, Falkum E, Aasland OG. The relationship between burnout and musculoskeletal pain in seven Norwegian occupational groups. Work. 2009;32(2):179-88. https://doi.org/10. 3233/Wor-2009-0804.

40. Honkonen T, Ahola K, Pertovaara M, Isometsä E, Kalimo R, Nykyri E, et al. The association between burnout and physical illness in the general population - results from the Finnish health 2000 study. J Psychosom Res. 2006;61(1):59-66. https://doi.org/10.1016/j.jpsychores.2005.10.002.

41. Hauke A, Flintrop J, Brun E, Rugulies R. The impact of work-related psychosocial stressors on the onset of musculoskeletal disorders in specific 
body regions: a review and meta-analysis of 54 longitudinal studies. Work Stress. 2011;25(3):243-56. https://doi.org/10.1080/02678373.2011.614069.

42. van der Windt DAWM, Thomas E, Pope DP, de Winter AF, Macfarlane GJ, Bouter LM, Silman AJ. Occupational risk factors for shoulder pain: a systematic review. Occup Environ Med. 2000;57(7):433-42. https://doi.org/ 10.1136/oem.57.7.433

43. Ariens GA, van Mechelen W, Bongers PM, Bouter LM, van der Wal G. Physical risk factors for neck pain. Scand J Work Environ Health. 2000;26(1): 7-19. https://doi.org/10.5271/sjweh.504.

44. Bongers PM, Kremer AM, ter Laak J. Are psychosocial factors, risk factors for symptoms and signs of the shoulder, elbow, or hand/wrist?: a review of the epidemiological literature. Am J Ind Med. 2002;41(5):315-42. https://doi.org/ 10.1002/ajim.10050.

45. Zhang J, Yu KF. What's the relative risk? A method of correcting the odds ratio in cohort studies of common outcomes. JAMA. 1998;280(19):1690-1. https://doi.org/10.1001/jama.280.19.1690.

46. Borenstein $M$, Hedges LV, Higgins JPT, Rothstein HR. Introduction to metaanalysis. Chichester: Wiley; 2009.

47. * Eriksen HR, Ihlebaek C, Jansen JP, Burdorf A. The relations between psychosocial factors at work and health status among workers in home care organizations. Int J Behav Med. 2006;13(3):183-92. https://doi.org/10.1207/ s15327558ijbm1303_1.

48. Hedges LV, Olkin I. Statistical methods for meta-analysis. New York: Academic; 1985

49. IntHout J, loannidis JP, Rovers MM, Goeman JJ. Plea for routinely presenting prediction intervals in meta-analysis. BMJ Open. 2016;6(7):e010247. https:// doi.org/10.1136/bmjopen-2015-010247.

50. * Alexopoulos EC, Burdorf A, Kalokerinou A. Risk factors for musculoskeletal disorders among nursing personnel in Greek hospitals. Int Arch Occup Environ Health. 2003;76(4):289-94. https://doi.org/10. 1007/s00420-003-0442-9

51. * Brage S, Sandanger I, Nygård JF. Emotional distress as a predictor for low back disability: a prospective 12-year population-based study. Spine. 2007; 32(2):269-74. https://doi.org/10.1097/01.brs.0000251883.20205.26.

52. Doerwald F, Scheibe S, Zacher H, Van Yperen NW. Emotional competencies across adulthood: state of knowledge and implications for the work context. Work Aging Retire. 2016;2(2):159-216. https://doi.org/10.1093/ workar/waw013.

53. * Elders LA, Burdorf A. Interrelations of risk factors and low back pain in scaffolders. Occup Environ Med. 2001;58(9):597-603. https://doi.org/10.1136/ oem.58.9.597.

54. * Eriksen W, Bruusgaard D, Knardahl S. Work factors as predictors of intense or disabling low back pain; a prospective study of nurses' aides. Occup Environ Med. 2004;61(5):398-404. https://doi.org/10.1136/oem.2003.008482.

55. * Feng CK, Chen ML, Mao IF. Prevalence of and risk factors for different measures of low back pain among female nursing aides in Taiwanese nursing homes. BMC Musculoskelet Disord. 2007;8:52. https://doi.org/10. 1186/1471-2474-8-52.

56. * Hooftman WE, van der Beek AJ, Bongers PM, van Mechelen W. Is there a gender difference in the effect of work-related physical and psychosocial risk factors on musculoskeletal symptoms and related sickness absence? Scand J Work Environ Health. 2009;35(2):85-95. https://doi.org/10.5271/ sjweh.1316.

57. * Hoogendoorn WE, Bongers PM, de Vet HC, Houtman IL, Ariens GA, van Mechelen W, et al. Psychosocial work characteristics and psychological strain in relation to low-back pain. Scand J Work Environ Health. 2001;27(4): 258-67. https://doi.org/10.5271/sjweh.613.

58. * Latza U, Pfahlberg A, Gefeller O. Impact of repetitive manual materials handling and psychosocial work factors on the future prevalence of chronic low-back pain among construction workers. Scand J Work Environ Health. 2002;28(5):314-23. https://doi.org/10.5271/sjweh.680

59. * Matsudaira K, Konishi H, Miyoshi K, Isomura T, Takeshita K, Hara N, et al. Potential risk factors for new onset of back pain disability in Japanese workers: findings from the Japan epidemiological research of occupationrelated back pain study. Spine (Phila Pa 1976). 2012;37(15):1324-33. https:// doi.org/10.1097/BRS.0b013e3182498382.

60. * Matsudaira K, Kawaguchi M, Isomura T, Inuzuka K, Koga T, Miyoshi K, et al. Assessment of psychosocial risk factors for the development of non-specific chronic disabling low back pain in Japanese workers-findings from the Japan epidemiological research of occupation-related back pain (JOB) study. Ind Health. 2015;53:368-77.
61. * Melloh M, Elfering A, Chapple CM, Kaser A, Rolli Salathe C, Barz T, et al. Prognostic occupational factors for persistent low back pain in primary care. Int Arch Occup Environ Health. 2013;86(3):261-9. https://doi.org/10.1007/ s00420-012-0761-9.

62. * Messing K, Stock SR, Tissot F. Should studies of risk factors for musculoskeletal disorders be stratified by gender? Lessons from the 1998 Québec health and social survey. Scand J Work Environ Health. 2009;35(2): 96-112. https://doi.org/10.5271/sjweh.1310.

63. * Tsigonia A, Tanagra D, Linos A, Merekoulias G, Alexopoulos EC. Musculoskeletal disorders among cosmetologists. Int J Environ Res Public Health. 2009;6(12):2967-79. https://doi.org/10.3390/ijerph6122967.

64. * van den Heuvel SG, Ariens GA, Boshuizen HC, Hoogendoorn WE, Bongers PM. Prognostic factors related to recurrent low-back pain and sickness absence. Scand J Work Environ Health. 2004;30(6):459-67. https://doi.org/10. 5271/sjweh.835.

65. * Violante FS, Fiori M, Fiorentini C, Risi A, Garagnani G, Bonfiglioli R, et al. Associations of psychosocial and individual factors with three different categories of back disorder among nursing staff. J Occup Health. 2004;46(2): 100-8. https://doi.org/10.1539/joh.46.100.

66. Kim MG, Seo Jl, Kim K, Ahn YS. Nationwide firefighter survey: the prevalence of lower back pain and its related psychological factors among Korean firefighters. Int J Occup Saf Ergon. 2017;23(4):447-56. https://doi.org/10. 1080/10803548.2016.1219149.

67. Min JY, Park SG, Kim SS, Min KB. Workplace injustice and self-reported disease and absenteeism in South Korea. Am J Ind Med. 2014;57(1):87-96. https://doi.org/10.1002/ajim.22233.

68. Zacher H, Schmitt A. Work characteristics and occupational well-being: the role of age. Front Psychol. 2016;7:1411. https://doi.org/10.3389/fpsyg.2016. 01411.

69. Tims M, Bakker AB, Derks D. Development and validation of the job crafting scale. J Vocat Behav. 2012;80(1):173-86. https://doi.org/10.1016/j. jvb.2011.05.009.

70. Wrzesniewski A, Dutton JE. Crafting a job: revisioning employees as active crafters of their work. Acad Manag Rev. 2001;26(2):179-201. https://doi.org/ 10.5465/Amr.2001.4378011.

71. * Cameron SJ, Armstrong-Stassen M, Kane D, Moro FB. Musculoskeletal problems experienced by older nurses in hospital settings. Nurs Forum. 2008;43(2):103-14. https://doi.org/10.1111/j.1744-6198.2008.00101.x.

72. Diebig M, Jungmann F, Muller A, Wulf IC, Diebig M, Jungmann F, Muller A, Wulf IC. Challenges for psychosocial risk assessment during the digital transformation of industry: a qualitative interview study. Z Arb Organ. 2018; 62(2):53-67. https://doi.org/10.1026/0932-4089/a000265.

73. Kholin M, Blickle G. The relationship between gainful employment, work values, and economic globalization: a psychosocial analysis. Z Arb Organ. 2015;59(1):16-29. https://doi.org/10.1026/0932-4089/a000169.

74. van der Doef M, Maes S. The job demand-control (-support) model and psychological well-being: a review of 20 years of empirical research. Work Stress. 1999;13(2):87-114. https://doi.org/10.1080/026783799296084.

75. Meucci RD, Fassa AG, Faria NMX. Prevalence of chronic low back pain: systematic review. Rev Saude Publica. 2015;49:1. https://doi.org/10.1590/ S00348910.2015049005874.

76. Hoy D, March L, Brooks P, Blyth F, Woolf A, Bain C, et al. The global burden of low back pain: estimates from the global burden of disease 2010 study. Ann Rheum Dis. 2014;73(6):968-74. https://doi.org/10.1136/annrheumdis2013-204428

77. Freburger JK, Holmes GM, Agans RP, Jackman AM, Darter JD, Wallace AS, et al. The rising prevalence of chronic low back pain. Arch Intern Med. 2009; 169(3):251-8. https://doi.org/10.1001/archinternmed.2008.543.

78. Hartvigsen J, Hancock MJ, Kongsted A, Louw Q, Ferreira ML, Genevay S, et al. What low back pain is and why we need to pay attention. Lancet. 2018;391(10137):2356-67. https://doi.org/10.1016/S0140-6736(18)30480-X.

79. Balagué F, Mannion AF, Pellisé F, Cedraschi C. Non-specific low back pain. Lancet. 2012;379(9814):482-91. https://doi.org/10.1016/S01406736(11)60610-7.

80. Pejtersen JH, Kristensen TS, Borg V, Bjorner JB. The second version of the Copenhagen psychosocial questionnaire. Scand J Public Healt. 2010;38(3 Suppl):8-24. https://doi.org/10.1177/1403494809349858.

81. Tabanelli MC, Depolo M, Cooke RMT, Sarchielli G, Bonfiglioli R, Mattioli S, et al. Available instruments for measurement of psychosocial factors in the work environment. J Int Arch Occup Environ Health. 2008:82(1):1-12. https://doi.org/10.1007/s00420-008-0312-6. 
82. Tomaschek A, Lanfer SSL, Melzer M, Debitz U, Buruck G. Measuring workrelated psychosocial and physical risk factors using workplace observations: a validation study of the "healthy workplace screening". Saf Sci. 2018; 101 (Supplement C):197-208. https://doi.org/10.1016/j.ssci.2017.09.006.

83. Buruck G, Tomaschek A, Lütke-Lanfer SS. Burnout prevention team -process evaluation of an organization health intervention. J Public Health. 2018:4:1-12.

84. Nielsen K, Abildgaard JS. Organizational interventions: a research-based framework for the evaluation of both process and effects. Work Stress. 2013; 27(3):278-97. https://doi.org/10.1080/02678373.2013.812358.

85. Bakker $A B$, Demerouti E. Job demands-resources theory: taking stock and looking forward. J Occup Health Psychol. 2017;22(3):273-85. https://doi.org/ 10.1037/ocp0000056.

86. Mierswa T, Kellmann M. Psychological detachment as moderator between psychosocial work conditions and low back pain development. Int J Occup Med Environ Health. 2017:30(2):313-27.

87. Wendsche J, Lohmann-Haislah A, Wegge J. The impact of supplementary short rest breaks on task performance - a meta-analysis. Sozialpolitikch. 2016. https://doi.org/10.18753/2297-8224-75.

88. Wendsche J, Lohmann-Haislah A. A meta-analysis on antecedents and outcomes of detachment from work. Front Psychol. 2017;7 https://doi.org/ 10.3389/Fpsyg.2016.02072.

89. Foster NE, Anema JR, Cherkin D, Chou R, Cohen SP, Gross DP, et al. Prevention and treatment of low back pain: evidence, challenges, and promising directions. Lancet. 2018;391(10137):2368-83. https://doi.org/10. 1016/S0140-6736(18)30489-6.

90. Hoffman BM, Papas RK, Chatkoff DK, Kerns RD. Meta-analysis of psychological interventions for chronic low back pain. Health Psychol. 2007; 26(1):1-9. https://doi.org/10.1037/0278-6133.26.1.1.

91. Mattioli S, Zanardi F, Baldasseroni A, Schaafsma F, Cooke RM, Mancini G, et al. Search strings for the study of putative occupational determinants of disease. Occup Environ Med. 2010;67(7):436-43. https://doi.org/10.1136/ oem.2008.044727.

\section{Publisher's Note}

Springer Nature remains neutral with regard to jurisdictional claims in published maps and institutional affiliations.

Ready to submit your research? Choose BMC and benefit from:

- fast, convenient online submission

- thorough peer review by experienced researchers in your field

- rapid publication on acceptance

- support for research data, including large and complex data types

- gold Open Access which fosters wider collaboration and increased citations

- maximum visibility for your research: over $100 \mathrm{M}$ website views per year

At BMC, research is always in progress.

Learn more biomedcentral.com/submissions 